\title{
Morphological study of prostate in different age groups of Indian population
}

\author{
KAYALVIZHI, I. ${ }^{1}{ }^{*}$, BHORIA, S. ${ }^{1}$, KHANAGWAL, V. P. $^{2}$ and NARAYAN, R. K. ${ }^{1}$ \\ ${ }^{1}$ Department of Anatomy, Pandit Bhagwat Dayal Sharma Post Graduate Institute of Medical Sciences, Rohtak, \\ 124001, Haryana, India \\ ${ }^{2}$ Department of Forensic Medicine, Pandit Bhagwat Dayal Sharma Post Graduate Institute of \\ Medical Sciences, Rohtak, 124001, Haryana, India \\ *E-mail: drkayalvizhi3@gmail.com
}

\begin{abstract}
Introduction: The prostate is a pyramidal shaped, fibromuscular glandular organ which surrounds the prostatic urethra. Three pathologic processes affect the prostate gland: Inflammation, Benign prostatic (Nodular) hyperplasia, and tumours. Of these three, the benign nodular hyperplasia and prostatic carcinoma are prevalent worldwide. Main treatment for both the above mentioned condition till date is surgical extraction of the prostate. A clear concept is required about the morphological features and measurements of prostate as it will play a major role in defining the disease and for the diagnosis. Material and Methods: The present study was conducted in the Department of Anatomy utilizing 50 samples of human prostate, age ranging from 10 to 80 years. The various morphological parameters studied were length, transverse diameter, antero-posterior diameter and weight of prostate. Results: The lowest and highest mean value were $1.76-2.79 \mathrm{~cm} ; 3.35-4.04 \mathrm{~cm} ; 1.65-2.30 \mathrm{~cm}$ and 16.8-26.6 gm for length, transverse diameter, antero-posterior diameter and weight respectively. Statistical measurements included mean, standard deviation, range and correlation coefficients of different parameters. Conclusions: Length and transverse diameter of prostate were maximum in the American population, Antero-Posterior diameter was maximum for Bangladeshi and weight was found maximum in Indian population.
\end{abstract}

Keywords: morphological study, prostate, weight of prostate.

\section{Introduction}

The prostate is a pyramidal shaped, fibro muscular glandular organ which surrounds the prostatic urethra. It is the largest accessory sex gland in the male reproductive system which surrounds the first part of urethra known as prostatic urethra. It produces a thin milky fluid, containing citric acid and acid phosphatase. The prostate is like an inverted cone in shape and resembles a chestnut in appearance in young adults and weighs about $8 \mathrm{gm}$. The various measurements of prostate are $4 \mathrm{~cm}$ transversely, $3 \mathrm{~cm}$ vertically and $2 \mathrm{~cm}$ antero-posteriorly, as observed and reported in standard texts by Glass and Mundy (2010), Eroschenko (2014) and Guyton and Hall (2006).

Three pathologic processes affect the prostate gland: Inflammation, Benign prostatic (Nodular) hyperplasia, and tumours. Of these three, the benign nodular hyperplasia is by far the most common and occurs so often in advanced age that they are taken as "normal" aging process as reported by Kumar, Abbas and Fausto (2005). Benign prostatic hyperplasia is an extremely common disorder in men over 50 years of age. It is characterized by hyperplasia of prostatic stromal and epithelial cells causing partial or virtually complete obstruction of the urethra. Diagnosis is done by ultrasound and clinical features and is confirmed by histopathological report along with Prostate-Specific Antigen (PSA) level.

Kumar, Abbas and Fausto (2005) observed that prostatic carcinoma is also an extremely common condition in men. Adenocarcinoma of the prostate is the most common form of cancer in men and the second leading cause of cancer death. Diagnosis is by rectal examination under anaesthesia together with cystoscopy, biopsy and by measuring Prostate specific antigen (PSA) level.

Main treatment for both the above mentioned condition till date is surgical extraction of the prostate. Hence, a clear concept is required about the morphological features and measurements of prostate as it will play a major role in defining the disease and for the diagnosis.

\section{Materials and Methods}

The present study was conducted in the Department of Anatomy in collaboration with the Department of Forensic Medicine, Pt. B. D. Sharma, University of Health Sciences, Rohtak. 50 samples of human prostate, age ranging from 10 to 80 years (Table 1 ) were collected from unclaimed dead bodies that were under examination in the mortuary of Department of Forensic Medicine. After legal formalities, the samples were collected within 24-36 hours of death to avoid any sign of putrefaction.

Bodies with signs of injury/ mutilation/ disfigurement before or after autopsy/ decomposition such as greenish discoloration in right iliac fossa were excluded. Particulars of the body i.e. Post-mortem report number, Date and time of death of the person, Date and time of post-mortem and appropriate age were noted from mortuary's record. 


\subsection{Steps of removal of prostate}

1. The midline incision on the anterior abdominal wall was extended up to the pubic symphysis.

2. Pubic symphysis was cut opened.

3. Side attachments of the prostate were removed; prostate was approximated by hand.

4. Urinary bladder was exposed. Transverse incision on lower part of urinary bladder was given and detached from upper $2 / 3^{\text {rd }}$ part.

5. Prostate's lower limit was approached with hand along with the bladder and cut at the membranous urethra level.

Soon after collection each sample was gently washed in tap water in a dissection tray. Blood and blood clots were removed as far as possible. The samples were tagged immediately, bearing a code number for subsequent identification. Then the samples were fixed in $10 \%$ formalin solution.

The prostate gland was separated from the urinary bladder and seminal vesicles by fine dissection retaining the capsule of the gland.

The collected samples were divided into three groups.

\subsection{Morphological parameters studied}

\section{Length of prostate}

2. Transverse diameter of prostate

3. Antero-posterior diameter of prostate

4. Weight of prostate

\subsection{Measurement procedure}

1.Length of prostate: Length of the prostate was measured from the center of base to the apex of prostate.

2.Transverse diameter of prostate: Transverse diameter was measured at the region of its maximum transverse level.

3.Antero-posterior diameter of prostate: Antero-posterior diameter was measured at the region of its highest antero-posterior convexity.

For the above parameters, Vernier Calliper was utilized. (Figures 1, 2)

4. Weight of prostate: The surfaces of each prostate were dried with blotting paper. Then the organ was weighed by means of an analytical balance in grams.

Observations were subjected to statistical analysis. ANOVA (multiple comparison) test, SPSS version 19 was used. Mean and standard deviations were computed for all quantitative variables.

1. Length of prostate: The mean \pm SD length of the prostate was $1.79 \pm 0.30 \mathrm{~cm}$ in group A ( 10 - 30 years, $2.33 \pm 0.46 \mathrm{~cm}$ in group B (31-60 years) and $2.79 \pm 0.49 \mathrm{~cm}$ in group $\mathrm{C}$ (61-80 years). The mean difference in length between group A, group B and group C was statistically significant $(\mathrm{p}<0.005)$. Positive correlation was present between length of prostate and age $(\mathrm{r}=+0.878 \mathrm{p}<0.001)$ (Table 2$)$.

2. Transverse diameter: The mean \pm SD transverse diameter of the prostate was $3.35 \pm 0.33 \mathrm{~cm}$ in group A ( 10 - 30 years), $3.68 \pm 0.42 \mathrm{~cm}$ in group B (31-60 years) and $4.04 \pm 0.35$ $\mathrm{cm}$ in group $\mathrm{C}$ (61-80 years). The highest mean transverse diameter was observed in group $\mathrm{C}$ and lowest mean was in group $\mathrm{A}$. The mean difference in transverse diameter between group $A$ and $C$ was statistically significant $(p<0.05)$. Positive correlation was present between transverse diameter of prostate and age $(r=+0.801 p<0.05)$. The mean difference in transverse diameter in group A \& B, group B \& C were found to be insignificant (Table 2).

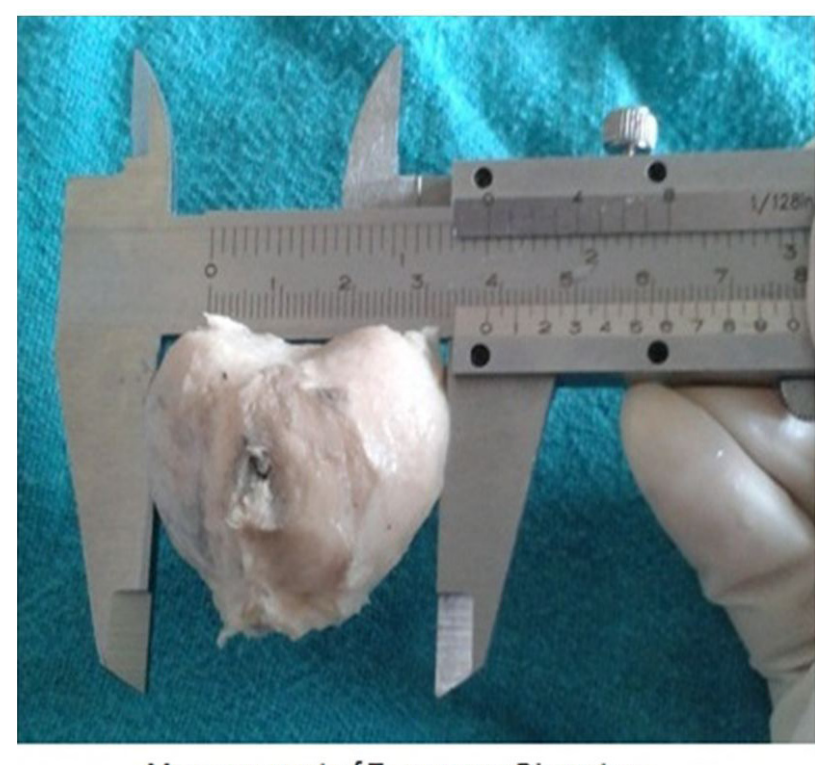

Measurement of Transverse Diameter

Figure 1. Measurement of the transverse diameter of human prostate.

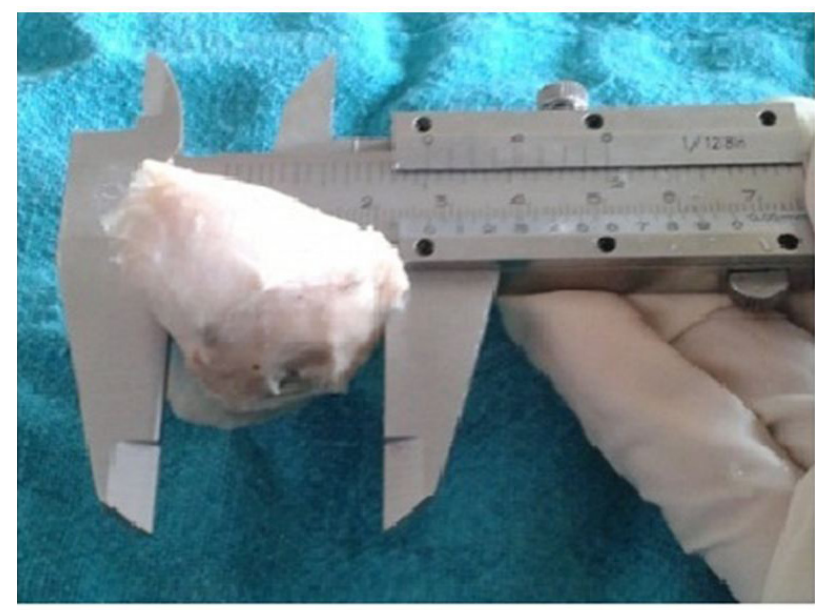

Measurement of Antero-Posterior Diameter

Figure 2. Measurement of the antero-posterior diameter of human prostate. 
3. Antero-posterior diameter: The mean $\pm \mathrm{SD}$ antero-posterior diameter of the prostate was $1.69 \pm 0.40 \mathrm{~cm}$ in group A (10-30 years), $2.24 \pm 0.36 \mathrm{~cm}$ group B (31-60 years) and $2.30 \pm 0.28 \mathrm{~cm}$ in group $\mathrm{C}(61-80$ years $)$. The highest mean antero-posterior diameter was observed in group $\mathrm{C}$ and lowest was in group $\mathrm{A}$. The mean difference in anteroposterior diameter between group A and C, group B and $\mathrm{C}$ was statistically significant $(\mathrm{p}<.001)$. Positive correlation was present between antero-posterior diameter and age $(\mathrm{r}=+0.732 \mathrm{p}<0.001)$. The mean difference in anteroposterior diameter was not significant between group $\mathrm{B}$ and $\mathrm{C}$ (Table 2).

4. Weight of prostate: The mean \pm SD weight of the prostate was $16.85 \pm 2.92 \mathrm{gm}$ in group A (10-30 years), $21.22 \pm 4.27 \mathrm{gm}$ in group B (31-60 years) and $26.65 \pm 7.74 \mathrm{gm}$ in group C (61-80 years). The highest mean weight was found in group $\mathrm{C}$ and the lowest mean weight was found in group A. The mean difference in weight between group $\mathrm{A}, \mathrm{B}$, and $\mathrm{C}$ was significant $(\mathrm{P}<0.001)$. Positive correlation was present between weight of the prostate and age $(r=+0.804$ $\mathrm{p}<0.001$ ) (Table 2)

\section{Discussion}

The present study has been conducted to see the morphological correlations utilized various parameters of prostate to provide data for Indian population particularly to North India (Haryanvi population).

The data of morphological parameters (length of prostate, transverse diameter, antero-posterior diameter and weight of the prostate gland) of our study was compared with existing literature. The morphological parameters stated in standard textbooks of Gray's anatomy as well as in textbook of pathology

Table 1. Distribution of age and number of samples in groups for morphological study.

\begin{tabular}{ccc}
\hline Group & Age limit (years) & No. of Samples \\
\hline A & $10-30$ & 20 \\
B & $31-60$ & 20 \\
C & $61-80$ & 10 \\
\hline
\end{tabular}

were considered for baseline data. These textbooks provide data for adult morphological detail of prostatic anatomy.

The morphological data available from Moore (1936) was for American population; Begum (1990), Ahmed, Ara, Begum et al. (2009) and Khan (1995) for Bangladeshi population were utilized for comparison with the current study of the Indian population as the age group of the specimen was from 10-80 years of age.

In our present study, length was $1.76-2.79 \mathrm{~cm}$. In majority, the value correlates with the text description as described by Rogers and Jacob (1992) and Glass and Mundy (2010).

The value of our study for prostate length correlates more or less similar to the study of Khan (1995) of Bangladeshi population.

The data of Moore (1936) and Ahmed, Ara, Begum et al. (2009) states that lowest and highest mean value was higher than our present study which depicts that the length in initial 2 decades was found to be $0.5-1 \mathrm{~cm}$ more in Bangladeshi and American population.

The transverse diameter of prostate as observed in the present study was 3.35-4.04 cm. Rogers and Jacob (1992), Glass and Mundy (2010) both observed the value of transverse diameter to be of $4 \mathrm{~cm}$ each respectively. The data of Ahmed, Ara, Begum et al. (2009) and Begum (1990) was lower than our study and Moore (1936) data was the highest.

From this study, it is clear that the transverse diameter of prostate was comparatively at a higher level in American population as reported by Moore (1936).

The present study reported antero-posterior diameter of prostate to be ranging from $1.69-2.30 \mathrm{~cm}$. The lowest mean value was less in our study and the highest mean value was higher in our study as compared to that of Moore (1936) data of American population. Data from Bangladeshi population reported by Begum (1990) and Ahmed, Ara, Begum et al. (2009) had lowest and the highest mean value to be higher than our present study.

Lowest mean value was observed to be lowest in our population only. In the American population highest mean value was $2.17 \mathrm{~cm}$; in our present study of Indian population it was $2.30 \mathrm{~cm}$ and that of Bangladeshi population was $2.6 \mathrm{~cm}$.

Kumar, Abbas and Fausto (2005), the editors for textbook of pathology states the weight as $20 \mathrm{gm}$. There was no data available from American population, while the present study reported the same to be in the range of 16.8-26.6 gm.

Table 2. Length, weight, antero- posterior diameter, transverse diameter of prostate in different study groups.

\begin{tabular}{ccccc}
\hline $\begin{array}{c}\text { Group } \\
(\mathbf{n})\end{array}$ & $\begin{array}{c}\text { Length (in cm) } \\
\text { mean } \pm \text { SD (Range) }\end{array}$ & $\begin{array}{c}\text { Weight (in gm) } \\
\text { mean } \pm \text { SD (Range) }\end{array}$ & $\begin{array}{c}\text { Antero- posterior } \\
\text { Diameter (in cm) } \\
\text { mean } \pm \text { SD (Range) }\end{array}$ & $\begin{array}{c}\text { Transverse Diameter } \\
\text { (in cm) }\end{array}$ \\
mean SD (Range)
\end{tabular}


Table 3. Comparison of measurements of all morphological parameters of prostate reported in present and previous studies.

\begin{tabular}{lcccc}
\hline \multicolumn{1}{c}{ AUTHORS } & LENGTH $(\mathrm{cm})$ & $\begin{array}{c}\text { TRANSVERSE } \\
\text { DIAMETER }(\mathrm{cm})\end{array}$ & $\begin{array}{c}\text { ANTERO- } \\
\text { POSTERIOR } \\
\text { DIAMETER }(\mathrm{cm})\end{array}$ & WEIGHT $(\mathrm{gm})$ \\
\hline Present study & $1.76-2.79$ & $3.35-4.04$ & $1.69-2.30$ & $16.8-26.6$ \\
Moore RA & $2.75-3.0$ & $3.60-4.37$ & $1.89-2.17$ & - \\
Begum S. & - & $3.21-4.08$ & $1.91-2.63$ & $11.2-24.1$ \\
Rukshana Ahmed & $2.36-2.72$ & $2.94-3.81$ & $1.92-2.6$ & $11.8-25.8$ \\
Roger \& Jacob & 2 & 4 & 2.5 & - \\
Glass \& Mundy & 3 & 4 & 2 & - \\
Khan S. H. & $2.0-2.96$ & - & - & - \\
McConnell & - & - & - & 18 \\
Kumar Abbas Fasto & - & - & - & 20 \\
\hline
\end{tabular}

Table 4. Morphological parameters of Prostate were compared to produce Correlation Coefficient.

\begin{tabular}{ccccc}
\hline $\begin{array}{c}\text { Correlation } \\
\text { Coefficient, }\end{array}$ & $\begin{array}{c}\text { Length Vs Transverse } \\
\text { Diameter }\end{array}$ & $\begin{array}{c}\text { Transverse Diameter } \\
\text { Vs Antero-Posterior }\end{array}$ & $\begin{array}{c}\text { Antero-Posterior Vs } \\
\text { Weight }\end{array}$ & $\begin{array}{c}\text { Length Vs } \\
\text { Antero-Posterior }\end{array}$ \\
\hline Group A & 0.764 & 0.322 & 0.870 & 0.611 \\
Group B & 0.856 & 0.887 & 0.899 & 0.782 \\
Group C & 0.735 & 0.348 & 0.623 & 0.724 \\
\hline
\end{tabular}

Table 5. Morphological parameters of Prostate were compared with age to produce Correlation Coefficient.

\begin{tabular}{lcccc}
\hline & Length vs Age & Tr. Dia. vs Age & Antero-Post. vs Age & Weight vs Age \\
\hline $\begin{array}{l}\text { Correlation } \\
\text { Coefficient, } r\end{array}$ & 0.878 & 0.801 & 0.732 & 0.804 \\
\hline
\end{tabular}

The mean value for weight was observed to be lowest in Bangladeshi population and the highest mean value was reported almost similar in all of the reported data.

\subsection{Correlation coefficient}

The correlation coefficient between various morphological parameters of the prostate is also significant in group A, B and C. Table 3 shows the group wise values of correlation coefficient between length, transverse diameter, antero-posterior diameter, weight and volume which shows a strong correlation observed between the parameters. For group A and B, strongest linear relationship was observed between antero-posterior and weight; that for group $\mathrm{C}$ was seen between length and transverse diameter as shown in Table 4.

Table 5 indicates the correlation of the measured parameters with age and was found maximum for length.

\section{Conclusions}

To summarize from our present study, lowest mean value for length and antero-posterior diameter for prostate was minimum in our population. For transverse diameter the lowest mean value was in midway between Bangladeshi and American population. Regarding weight of prostate, the lowest mean value was maximum in our study of Indian population.

The highest mean value for length, transverse diameter and antero-posterior diameter in our study of Indian population remained midway between Bangladeshi and American population and that for weight of prostate was maximum, suggesting average weight in group $\mathrm{C}$ specimen was increased. An exclusive specimen of $\mathrm{BPH}$ with highest weight was also found.

To conclude, Length and transverse diameter of prostate were maximum in American population, Antero-Posterior diameter was maximum for Bangladeshi and weight was found maximum in Indian population.

Acknowledgements: The funding\& technical support was provided by Pt. B. D. S. University of Health Sciences, PGIMS, Rohtak, Haryana, India.

\section{Refrences}

AHMED, R., ARA, S., BEGUM, M., KISHWARA, S., RAYHAN, K., MAHBUB, S., BEGUM, T. Morphological study on age related changes of the prostate. Bangladesh Journal of Anatomy, 2009, vol. 7, p. 68-72.

BEGUM, S. An anatomical study of age changes of prostate in Bangladeshi people. Dhaka: University of Dhaka, 1990. 37 p.

EROSCHENKO, VP. Difiore's atlas of histology with functional correlation. 12th ed. New Delhi: Wolters Kluwer, 2014. p. 495-497.

GLASS, J. and MUNDY, AR. (Eds.) Abdomen and pelvis. In STANDRING, S., ELLIS, H., HEALY, JC., JOHNSON, D., WILLIAMS, A. and COLLIN, P. (Eds.). Gray's anatomy. 40th ed. London: Elsevier Churchill Livingstone, 2010. p. 1257-1259.

GUYTON, AC. and HALL, JE. Textbook of medical physiology. 11 th ed. Philadelphia: W.B. Saunders Company, 2006. 916-20 p.

KHAN, SH. Gross and histomorphological study of the prostate: an age perspective in Bangladeshi males. Dhaka: University of Dhaka, 1995.

KUMAR, V., ABBAS, AK. and FAUSTO, N. Pathologic basis of disease. 7th ed. New Delhi: W.B. Saunders Company, 2005. p. 1047-1056.

MOORE, RA. The evolution and involution of the prostate gland. American Journal of Pathology, 1936, vol. 12, n. 5, p. 599-624, 7. PMid:19970289.

ROGERS, AW. and JACOB, S. Textbook of Anatomy. Edinburgh: Churchill Livingstone, 1992. p. 648-684.

Received July 8, 2016 Accepted February 28, 2017 